\section{Discussion}

The present investigation suggests that the use of oral contraceptives before a surgical operation increases the subsequent risk of postoperative thromboembolism threefold to fourfold. The magnitude of the relative risk is thus estimated to be somewhat less than that previously found for thromboembolism occurring in the absence of predisposing factors (Vessey and Doll, 1968, 1969). It should be noted, however, that the number of patients in the present study was necessarily small and that the confidence limits of the estimate are wide.

This finding raises the question of whether or not patients should be advised to discontinue oral contraceptives for a while before undergoing elective surgical procedures. To find out about the existing practices in this respect, we included a special question in the postal inquiry that we made of the 50 general surgeons referred to previously. While only. $10 \%$ of them stated that they advised young women to discontinue oral contraceptives for an interval before undergoing elective surgery during 1964-7, no fewer than half stated that this was their practice now. As always, however, the risks of oral contraception have to be balanced against the risks of unwanted pregnancy. These are not inconsiderable; and one surgeon commented, "I started to advise discontinuing oral contraceptives, but two patients promptly became pregnant. I have now reversed my decision. I fear the unwanted pregnancy more than the pill."

If oral contraceptives are to be stopped before elective surgery, for how long should they be stopped? The present investigation, and those that we made earlier, suggest that the increased risk of thromboembolism declines rapidly after discontinuation of medication, to become undetectable after four weeks. This finding is also in keeping with studies of the effects of oral contraceptives on blood clotting, in which it has been shown. that changes brought about by oral contraceptives return to normal within a few weeks of stopping (Dugdale and Masi, 1969).

We should like to express our thanks to Miss Keena Jones for tracing and interviewing the patients and to Dr. Patricia Fraser for assessing the case histories.

The investigation would not have been $;$ ossible without the cooperation of many consultants, general practitioners, and hospital records officers and we are most grateful for their help.

\section{REFERENCES}

Acheson, E. D. (editor) (1968). In Record Linkage in Medicine, p. 40. Edinburgh, Livingstone.

Dugdale, M., and Masi, A. T. (1969). In Second Report on the Oral Contraceptives by the Advisory Committee on Obstetrics and Gynecology. Washington,-D.C., U.S. Department of Health, EducaGynecology. Washington, D.C., U.S. Department
tion and Welfare, Food \& Drug Administration.

Flanc, C., Kakkar, V. V., and Clarke, M. B. (1968). British fournal of Surgery, 55, 742.

Inman, W. H. W., and Vessey, M. P. (1968). British Medical fournal, $2,193$.

Inman, W. H. W., Vessey, M. P., Westerholm, B., and Engelund, A. (1970). British Medical fournal, 2, 203.

Kemsley, W. F. F., Billewicz, W. Z., and Thomson, A. M. (1962). British fournal of Preventive and Social Medicine, 16, 189.

Lambie, J. M., et al. (1970). British Medical fournal, 2, 142.

Mantel, N., and Haenszel, W. (1959). Fournal of the National Cancer Institute, 22, 719.

Pike, M. C., and Morrow, R. H. (1970). British fournal of Preventive and Social Medicine, 24, 42.

Royal College of General Practitioners (1967). Fournal of the Royal College of General Practitioners, 13, 267.

Sartwell, P. E., Masi, A. T., Arthes, F. G., Greene, G. R., and Smith, H. E. (1969). American fournal of Epidemiology, 90, 365

Vessey, M. P. (1970). M.D. Thesis. In preparation.

Vessey, M. P., and Doll, R. (1968). British Medical fournal, 2, 199.

Vessey, M. P., and Doll, R. (1969). British Medical fournal, 2, 651.

\title{
Relevance of Salt, Water, and Renin to Hypertension in Chronic Renal Failure
}

\author{
G. S. STOKES, ${ }^{*}$ M.D., M.R.A.C.P. ; M. K. MANI, $\dagger$ M.D. ; J. H. STEWART, $\ddagger$ M.R.C.P., M.R.A.C.P.
}

\begin{abstract}
Cummary: Blood pressure control was examined in 75 $\checkmark$ patients with end-stage renal failure treated by regular twice-weekly haemodialysis. Dietary sodium was restricted and extracellular fluid was removed by ultrafiltration until blood pressure was normal or signs of salt depletion were observed. Failure of these measures constituted an indication for nephrectomy. Of the 75 patients, 18 were never hypertensive, 46 had hypertension which could be corrected by salt and water depletion, and 11 had persistent hypertension which could not be controlled in this way. Nine of these 11 patients underwent bilateral nephrectomy; in each of the seven in whom the post operative result could be evaluated the blood pressure returned rapidly to normal.
\end{abstract}

Plasma renin activity, measured in 34 subjects, was raised above normal in six out of nine patients whose

\footnotetext{
* Senior Research Fellow, National Heart Foundation of Australia. † Physician, Dialysis and Transplantation Unit. $¥$ Renal Physician.

Medical Research Department, Kanematsu Memorial Institute, Sydney Hospital, Sydney, N.S.W., 2000, Australia.
}

blood pressure could not be controlled by salt and water depletion and in one of the 11 patients whose blood pressure could be so controlled, but was within the normal range in all nine normotensive patients. The mean level of plasma renin activity in the first group was significantly higher than that of each of the other two groups.

There was a significant correlation between hypertension during dialysis and after transplantation, suggesting that, in addition to renin, there is a non-renal factor which predisposes certain patients to hypertension in the presence of salt and water excess.

\section{Introduction}

While it has been claimed that hypertension in patients with end-stage renal failure can always be controlled by adequate ultrafiltration during dialysis coupled with restriction of dietary sodium (Blumberg et al., 1964; Comty et al., 1964; McDonald, 1967) there are patients in whom blood pressure cannot be controlled by sodium depletion until both 
kidneys are removed (Seto et al., 1963; Toussaint et al., 1967; Onesti et al., 1968; Vertes et al., 1969). Toussaint et al. (1967) observed that such patients often had a high plasma concentration of renin, and we reported that plasma renin activity was greater in each of eight patients whose blood pressure could not be satisfactorily controlled by dialysis alone than in six whose blood pressure was readily controlled by this means (Stokes and Stewart, 1968). Vertes et al. (1969) reported a similar experience in 40 hypertensive patients with end-stage renal disease; five of these had hypertension despite dialysis to dry weight and serum renin values higher than the remainder.

The present report extends our preliminary observations to 75 patients on maintenance haemodialysis and five with uncontrollable hypertension and advancing renal failure. Plasma renin activity was determined in 34 of these patients.

\section{Patients and Methods}

Seventy-five patients with end-stage renal failure were studied before and during maintenance haemodialysis treatment, which was carried out in each case for at least one month (Table I). A second group comprised five patients who

TABLE I.-Diagnostic Subgroups

\begin{tabular}{|c|c|c|c|c|c|c|c|c|c|}
\hline & & & 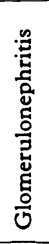 & 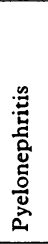 & 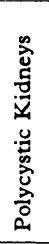 & 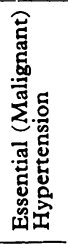 & 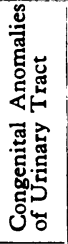 & 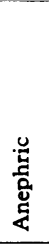 & Total \\
\hline $\begin{array}{l}\text { Normotensive } \\
\text { Hypertensive .. }\end{array}$ & & $\begin{array}{l}\cdots \\
\cdots\end{array}$ & $\begin{array}{l}10 \\
30\end{array}$ & $\begin{array}{r}6 \\
17\end{array}$ & $\begin{array}{l}1 \\
4\end{array}$ & $\begin{array}{l}0 \\
2\end{array}$ & $\begin{array}{l}2 * \\
1+\end{array}$ & $\begin{array}{l}1 \neq \\
1 \oint\end{array}$ & $\begin{array}{l}20 \\
55\end{array}$ \\
\hline Total & . & . & 40 & 23 & 5 & 2 & 3 & 2 & 75 \\
\hline
\end{tabular}

* One horseshoe kidney, one congenital bladder-neck obstruction and vesicoureteric reflux.

$\ddagger$ Bilateral nephrectomy done for carcinomata in both kidneys, the second some years after the first.

$\$$ Bilateral nephrectomy done for essential hypertension in the malignant phase.

suffered from severe, rapidly worsening hypertension which could not be controlled by antihypertensive drugs and for which emergency bilateral nephrectomy appeared to be the only feasible treatment. Four of these patients had essential hypertension and the fifth chronic glomerulonephritis. One of them subsequently received maintenance haemodialysis and therefore figures in both groups.

The dialysis regimen consisted of twice-weekly treatments, each of six to eight hours, with a Travenol artificial kidney. The sodium concentration in the dialysis solution was $130-135$ mEq per litre. During each treatment the patient's weight was restored to an "ideal" level-that is, the weight at which blood pressure was normal and there was no clinical evidence of overhydration or, in those patients whose blood pressure could not be controlled by extracellular fluid depletion, the lowest weight which could be attained without causing postural hypotension, weakness, nausea, or muscular cramps. Blood pressure was measured with the patient recumbent, before and after each treatment. Between dialyses, weight gain was restricted to $0.5 \mathrm{~kg}$. per day by prescribino a diet containing $20 \mathrm{mEq}$ of sodium per day and by restricting fluid intake when necessary. All antihypertensive drugs were stopped at the start of regular dialysis treatment, being restarted in only two patients-in one before nephrectomy for hypertension, in the other because of persistent hypertension due to inadequate control of dietary sodium and water.
Initially, three patients underwent bilateral nephrectomy without a specific indication in preparation for transplantation. Thereafter, this operation was performed only for hypertension not controlled by dialysis, active pyelonephritis, polycystic kidneys, or congenital abnormalities of the urinary tract.

In nine of the normotensive and 25 of the hypertensive patients plasma renin activity was determined at the time of initiating maintenance 'dialysis, or between regular dialyses. For each determination $30-50 \mathrm{ml}$. of venous blood was taken between 8 and 10 a.m. after the patient had been sitting upright for one to two hours, and renin activity was bioassayed by the method of Boucher et al. (1964). Eleven studies were carried out to investigate the immediate effects of haemodialysis on plasma renin activity. One plasma sample was taken in the morning, just before a regular dialysis, and a second one after completing dialysis, either on the same afternoon or on the following morning. Measurements of blood pressure, serum sodium concentration, and body weight were made at the same time as plasma was collected for bioassay. The range of plasma renin activity determined in 10 normal subjects in the upright posture while receiving a diet containing $100 \mathrm{mEq}$ of sodium per day was 0.2 to $1 \mu \mathrm{g} . / 100 \mathrm{ml}$.

\section{Results}

\section{Clinical Observations}

At the beginning of their treatment, 55 of the 75 patients on maintenance dialysis had hypertension, defined as a mean diastolic blood pressure of $100 \mathrm{~mm}$. $\mathrm{Hg}$ or more during the month before starting regular haemodialysis. Twenty had a normal blood pressure and were not receiving antihypertensive drugs at that time (Table I). In 44 of the 55 originally hypertensive patients the blood pressure could be maintained within normal limits by extracellular fluid depletion, though in 19 of them hypertension returned when their weight was higher than "ideal" (Table II). At their "ideal" weight all felt

TABLE II.-Control of Hypertension by Maintenance Haemodialysis

\begin{tabular}{|c|c|c|c|c|c|c|c|c|}
\hline & & 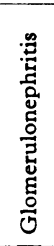 & 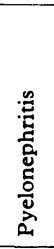 & 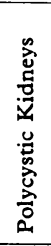 & 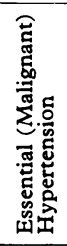 & 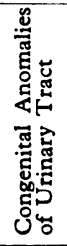 & 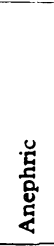 & Total \\
\hline $\begin{array}{l}\text { Controlled } \\
\text { Controlled at ideal weight } \\
\text { Uncontrollable }\end{array}$ & $\begin{array}{l}\cdots \\
\cdots\end{array}$ & $\begin{array}{r}14 \\
11 \\
5\end{array}$ & $\begin{array}{l}9 \\
5 \\
3\end{array}$ & $\begin{array}{l}1 \\
2 \\
1\end{array}$ & $\begin{array}{l}0 \\
0 \\
2\end{array}$ & $\begin{array}{l}0 \\
1 \\
0\end{array}$ & $\begin{array}{l}1^{*} \\
0 \\
0\end{array}$ & $\begin{array}{l}25 \\
19 \\
11\end{array}$ \\
\hline Total & . & 30 & 17 & 4 & 2 & 1 & 1 & 55 \\
\hline
\end{tabular}

well and had a normal blood pressure. This group included the patient who had undergone emergency nephrectomy before regular haemodialysis (see below).

The other 11 patients had hypertension which could not be corrected by regular haemodialysis and dietary measures. Persistence with extracellular fluid depletion beyond a certain point resulted in severe symptoms of salt and water depletion, with postural hypotension. Restoration of extracellular fluid volume sufficient to alleviate these symptoms was associated with a return of blood pressure to raised levels. One of these patients, who had chronic glomerulonephritis, had a normal blood pressure during the first four months of dialysis but subsequently developed hypertension which could not be controlled by dialysis. Nine of the 11 patients underwent bi- 
lateral nephrectomy-seven became normotensive (range of mean blood pressure before nephrectomy $117-158 \mathrm{~mm}$. $\mathrm{Hg}$, after nephrectomy 88-117 mm. $\mathrm{Hg}$ ), one died, and one underwent transplantation in the early postoperative period. Both the patients who had not undergone nephrectomy were still being treated with methyldopa, one after renal transplantation, the other while being trained for haemodialysis in his own home. Blood pressure remained normal in 18 of the 20 initially normotensive patients, but two developed reversible hypertension due to excessive intake of salt and water.

Fifty of these patients have received a cadaveric renal allograft which functioned satisfactorily. Subsequently, 16 of them developed hypertension, requiring treatment with methyldopa (Table III). Hypertension after successful transplantation could not be related to the presence or absence of the kidneys, but there was a correlation between hypertension during dialysis (whether or not controlled by salt and water depletion) and after transplantation $\left(\chi^{2}=8.1 ; P<0.005\right)$.

TABLE III.-Blood Pressure after Transplantation

\begin{tabular}{|c|c|c|c|c|}
\hline \multicolumn{2}{|l|}{ Control on Dialysis } & \multirow{2}{*}{ Transplanted } & \multicolumn{2}{|c|}{$\begin{array}{l}\text { Blood Pressure After } \\
\text { Transplantation }\end{array}$} \\
\hline & & & Hypertensive & Normotensive \\
\hline $\begin{array}{l}\text { Controlled: } \\
\text { Own kidneys removed } \\
\text { Own kidneys retained } \\
\text { Controlled at ideal weight: } \\
\text { Own kidneys removed } \\
\text { Own kidneys retained } \\
\text { Uncontrolled: } \\
\text { Own kidneys removed } \\
\text { Own kidneys retained }\end{array}$ & $\begin{array}{l}\cdots \\
\ldots \\
\cdots \\
\cdots \\
\cdots\end{array}$ & $\begin{array}{r}7 \\
23 \\
5 \\
9 \\
5 \\
1\end{array}$ & $\begin{array}{l}2 \\
3 \\
2 \\
7 \\
1 \\
1\end{array}$ & $\begin{array}{r}5 \\
20 \\
3 \\
2 \\
4 \\
0\end{array}$ \\
\hline Total & $\ldots$ & 50 & 16 & 34 \\
\hline
\end{tabular}

Of the five patients thought to require emergency nephrectomy two died before the operation could be undertaken. Blood pressure returned to normal immediately after bilateral nephrectomy in the other three, one of whom was continued on maintenance haemodialysis and remained normotensive.

\section{Plasma Renin Activity and Blood Pressure}

The results obtained for plasma renin activity in 28 of the patients on maintenance dialysis are shown as black circles in

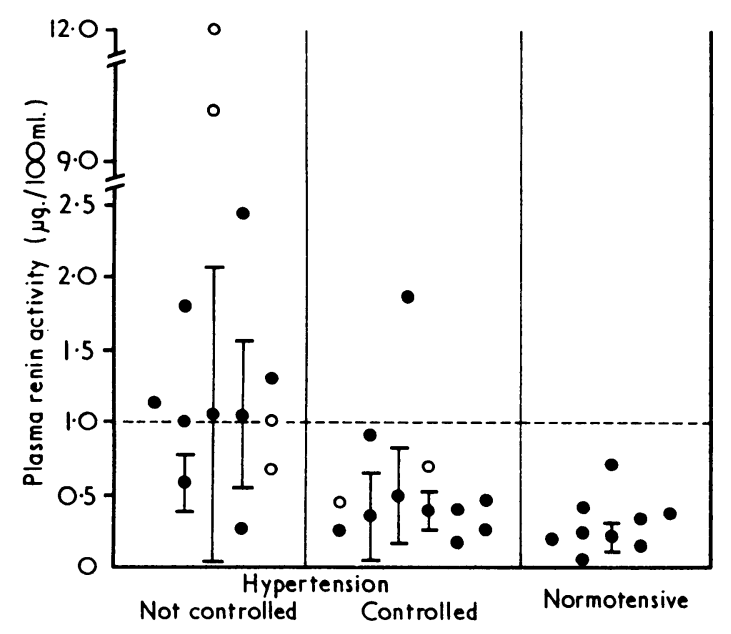

FIG. 1.-Single values (circles) or mean values \pm S.D. (circles and bars) for plasma renin activity in 13 patients with severe renal failure whose hypertension was uncontrollable (first column), in 12 whose diastolic
blood pressure could be kept below $100 \mathrm{~mm}$. Hg by dialysis (second blood pressure could be kept below $100 \mathrm{~mm}$. Hg by dialysis (second
column), and in 9 whose blood pressure was always normal (third column), after 3 to 72 twice-weekly dialyses (black circles) or before regular dialysis (white circles).
Fig. 1. In seven patients the values shown are the mean of two to six observations made on different days; in the remainder the values are based on a single determination. Plasma renin activity averaged $1.18 \pm 0.21$ (S.E.) $\mu \mathrm{g} . / 100 \mathrm{ml}$. in nine patients whose blood pressure could not be controlled by regular haemodialysis (first column, Fig. 1), $0.55 \pm 0.16$ (S.E.) $\mu \mathrm{g} . / 100 \mathrm{ml}$. in 10 patients whose hypertension was controlled by dialysis (second column), and $0.29 \pm 0.06$ (S.E.) $\mu \mathrm{g} . / 100 \mathrm{ml}$. in nine patients whose blood pressure was normal throughout. The result in the first of these groups is significantly greater than in the other two $(P<0.05$ and $\mathbf{P}<0.005$ respectively), but the difference in plasma renin activity between the second and third groups was not significant $(\mathrm{P}<0.2)$.

Comparison of relevant features in the patients of the first two groups showed no other factor sufficient to account for the different responses to treatment: The duration of maintenance dialysis did not differ significantly-the median number of dialyses in the first group was 12 and in the second group nine; serum sodium concentration averaged $132 \pm$ 1.7 (S.E.) $\mathrm{mEq} / 1$. in the first group and $133 \pm 2.2$ (S.E.) $\mathrm{mEq} / 1$. in the second group; the initial blood pressure was similar in the patients of both groups. Patients in the first group, however, had more severe retinopathy (all had grade III or IV) than those in the second group, of whom only four had grade III or IV changes. Similarly, the incidence of cardiac failure was greater in the first group (56\%) than in the second $(30 \%)$. The two patients who had encephalopathy were in the second group.

In six patients plasma renin activity was determined before regular dialysis had been started. The values obtained are shown as white circles in Fig. 1. In two of these patients the blood pressure was subsequently controlled by dialysis alone. One of these had grade III retinopathy, the other grade II; both had cardiac failure. In both the value for plasma renin activity (shown in second column, Fig. 1) was within the normal range. The other four patients had severe, rapidly worsening hypertension considered to require urgent bilateral nephrectomy. All had grade III or IV retinopathy and cardiac failure; two of them had frequent episodes of hypertensive encephalopathy. Plasma renin activity was very high in two of these cases. In the other two it was initially normal, but increased greatly during preoperative peritoneal dialysis. The results obtained in one of these patients are shown in Fig. 2. Despite removal of more than $10 \mathrm{~kg}$. of excess body fluid by dialysis in two days, there was no appreciable improvement in blood pressure. Plasma renin activity, however, increased tenfold, suggesting that fluid or electrolyte factors may have been suppressing the release of renin.

The values depicted by black circles in Fig. 1 were all determined from samples collected three to four days after dialysis and on the morning before the next regular dialysis. In this way any transient increments in circulating renin induced by acute changes in body fluid and electrolyte composition were avoided. Though pronounced changes in plasma renin activity were seen in the two patients who underwent prolonged peritoneal dialysis, mean plasma renin activity did not change significantly in 11 patients studied before and after haemodialysis (Fig. 3). Weight loss during dialysis averaged $2.1 \mathrm{~kg}$. (range 0.3-3.8 kg.) in this group. Plasma renin activity was not related to weight loss during dialysis, and increased appreciably in only two patients.

Following bilateral nephrectomy plasma renin activity fell rapidly to low levels. Two to three months postoperatively no renin could be detected in the plasma of three patients, and levels less than $0.2 \mu \mathrm{g} . / 100 \mathrm{ml}$. were found in two patients. One patient with initially high plasma renin activity and uncontrollable hypertension was studied again after bilateral nephrectomy and successful renal transplantation; plasma renin activity had fallen to a value within the normal range. 

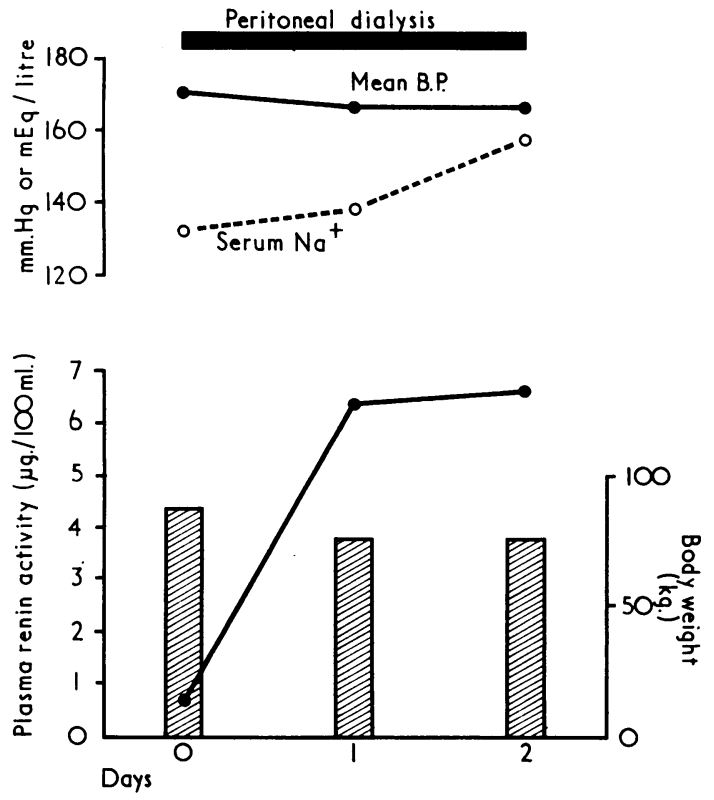

FIG. 2.-Values for mean blood pressure (diastolic pressure plus onethird of pulse pressure), serum sodium concentration, plasma renin activity, and body weight in a patient with severe renal failure, malignant hypertension, and hypertensive encephalopathy during peritoneal dialysis.

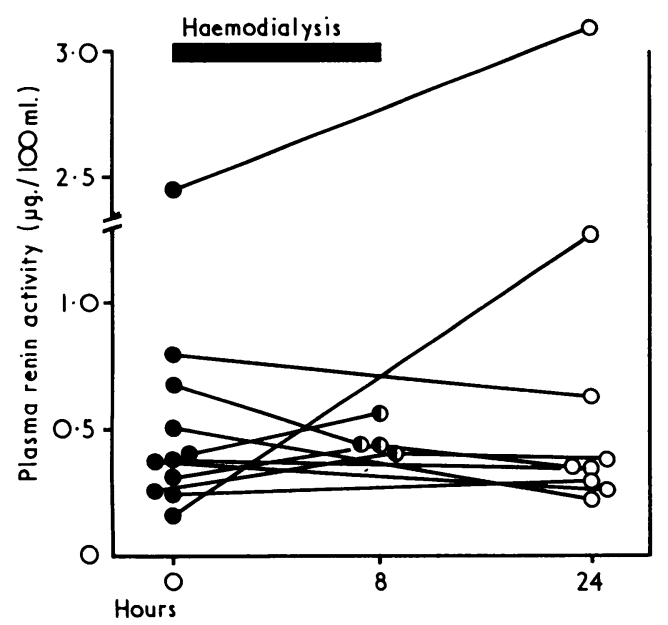

FIG. 3.-Plasma renin activity at 8 a.m. just before haemodialysis (black circles), at 4 p.m. after completion of an eight-hour haemodialysis treatment (half-black circles), and at $8 \mathrm{a} . \mathrm{m}$. the next day (white circles) in 11 patients with severe renal failure.

\section{Discussion}

Patients with hypertension and severe renal failure appear to fall into two categories, first clearly defined by Vertes $e t$ al. (1969), and confirmed in the present study. The first comprises those whose blood pressure remains normal in the absence of excess salt and water, but is raised when the "ideal" weight is exceeded-the "salt-water-dependent" hypertension of the Cleveland authors. In the present series only one such patient had a raised plasma renin activity. The second group have hypertension that cannot be controlled by depletion of salt and water but does respond to removal of both kidneys. In the present series plasma renin activity was raised in most, but not all, such patients, to whose condition the Cleveland authors applied the term "renin-dependent hypertension."

Of our five patients with hypertension too severe to permit a prolonged trial of dialysis treatment two had normal plasma renin activity when first tested. It is difficult to postulate that their hypertension was entirely dependent on circulating renin, yet they undoubtedly belonged to the second category for their blbod pressure, though not improved by salt and water depletion (see Fig. 2), did respond promptly to bilateral nephrectomy. In both these patients plasma renin activity rose as a result of salt and water depletion.

Does a raised level of plasma renin activity in patients with "renin-dependent hypertension" merely reflect more salt and water depletion resulting from more vigorous therapy by diet, diuretics, and dialysis? Since plasma or extracellular fluid volume was not measured, our studies provide no final answer to this question. Nevertheless, the conditions under which plasma samples were collected for renin assay in this series were chosen so as to minimize the effects of inadequate or excessive dialysis. Thus observations were made several weeks after starting regular dialysis where possible, and after at least three days from the previous dialysis. Moreover, in the studies carried out before and immediately after single haemodialysis treatments there was an early increase in plasma renin activity in only two cases out of 11 .

A group of patients who should not be forgotten are those with severe renal failure, often with obvious oedema or congestive heart failure, but whose blood pressure remains normal. Plasma renin activity was low in all such patients studied. We do not know how their blood pressure would respond to a renin-producing lesion of the kidneys. Patients in this group did not become hypertensive after transplantation, whereas hypertension of either variety during dialysis was related to hypertension after transplantation, and the presence or absence of the patient's own kidneys made little difference to this relationship. This suggests that there is a non-renal factor which makes a patient respond to excess renin or salt and water by developing hypertension.

This work was supported by grants from the National Heart Foundation of Australia and the National Health and Medical Research Council of Australia. We thank Dr. J. R. Johnson, Dr. R. Evans, Dr. F. C. Neale, Sister Thelma Jones, Mrs. Lynette Stoker, and the nursing staff of the Transplantation and Dialysis Unit, Sydney Hospital, for valuable medical, scientific, and technical assistance.

\section{REFERENCES}

Blumberg, A., Hegstrom, R: M., and Nelp, W. B. (1964). In Proceedings of the 1st Conference of the European Dialysis and Transplant Association, ed. D. N. S. Kerr, p. 199. Amsterdam, Scheltma and Holima.

Boucher, R., Veyrat, R., de Champlain, J., and Genest, J. (1964). Canadian Medical Association Fournal, 90, 194.

Comty, C., Rottka, H., and Shaldon, S. (1964). In Proceedings of the Ist Conference of the European Dialysis and Transplant AssociaIst Conference of the European Dialysis and Transplant Associa-
tion, ed. D. N. S. Kerr, p. 209. Amsterdam, Scheltma and Holima.

McDonald, H. P., jun. (1967). In Replacement of Renal Function: Proceedings of the 3rd Conference of the European Dialysis and Transplant Association, ed. D. N. S. Kerr, p. 73. Amsterdam, Excerpta Medica.

Onesti, G., Swartz, C., Ramirez, O., and Brest, A. N. (1968). Transactions. American Society for Artificial Internal Organs, 14, 361.

Seto, D., Fritz, W., Nakamoto, S., and Kolff, W. J. (1963). Transactions. American Society for Artificial Intermal Organs, 9, 35.

Stokes, G. S., and Stewart, J. H. (1968). Australasian Annals of Medicine, 17, 351 .

Toussaint, Ch., et al. (1967). In Replacement of Renal Function: Proceedings of the 3rd Conference of the European Dialysis and Transplant Association, ed. D. N. S. Kerr, p. 65. Amsterdam, Excerpta Medica.

Vertes, V., Cangiano, J. L., Berman, L. B., and Gould, A. (1969). New England Fournal of Medicine, 280, 978. 